\title{
Physiological influence of tylosin tartrate overdose in vivo in rats
}

\author{
JeongWoo Kang ${ }^{1}$, Md Akil Hossain ${ }^{1}$, Hae-chul Park¹, Tae-wan Kim², Sang-Hee Jeong³ \\ ${ }^{1}$ Veterinary drugs \& Biologics Division, Animal and Plant Quarantine Agency (APQA), \\ Gimcheon-si, Gyeongsangbuk-do, Republic of Korea \\ ${ }^{2}$ Department of Physiology, College of Veterinary Medicine, Kyungpook National University, \\ Daegu, Republic of Korea \\ ${ }^{3}$ GLP Research Center, College of Natural Sciences, Hoseo University, \\ Asan City, Republic of Korea \\ Received November 13, 2019 \\ Accepted June 22, 2020
}

\begin{abstract}
The aim of this study was to evaluate the physiological effects of tylosin in rats. Tylosin was administered orally to pubertal male and female rats at concentrations of $0.005,0.2,10$ and $200 \mathrm{mg} / \mathrm{kg} \mathrm{b.w}$. for 6 weeks. The overall body and organ weights were recorded. Serum levels of immunoglobulins, haematological values, histopathological lesions in different organs, and gene expression profiles in pituitary glands were investigated. The mean platelet volume was increased, and the monocyte count was decreased significantly in both male and female rats treated with tylosin. Compared to the untreated control, alanine transaminase in both types of rats and total serum bilirubin in female rats were increased significantly with the administration of tylosin $(200 \mathrm{mg} / \mathrm{kg})$, however, lactate dehydrogenase in female rats was decreased. The levels of immunoglobulin $\mathrm{M}$ were reduced in both male and female rats but immunoglobulin $\mathrm{G}$ levels were significantly reduced only in female rats which were treated with tylosin. Cell proliferation- and adhesion-associated genes were expressed more but apoptosis gene expressions were decreased in the pituitary gland of tylosin-treated rats. In conclusion, this study revealed that the use of tylosin at therapeutic dosage is possibly not completely safe.
\end{abstract}

Immunoglobulins, histopathology, physiology, toxicity, tylosin

Tylosin is one of the most commonly used macrolide antibiotics in veterinary medicine for the treatment of a wide range of infections in domestic animals. This agent is active against most Gram-positive bacteria, mycoplasma and certain Gram-negative bacteria. Hence, tylosin is widely used for the treatment of various infectious diseases in livestock animals (Bhaumik et al. 1990; McOrist et al. 1997; Baggesen et al. 1999; Vissiennon et al. 2000). Generally, the dosage of veterinary antibiotics is higher, and particularly for tylosin the dosage is $10 \mathrm{mg} / \mathrm{kg} /$ day for 15 days. Few studies have already shown diverse side effects when tylosin is administered to animals. For example, tylosin showed moderate effects on the splenocyte proliferation, splenocyte conditioned medium proliferative activity, and splenocyte anti-tumour activity in chicken (B aba et al. 1998a). It has also been reported that tylosin has an effect on increasing the antibody production and can modulate the number of antibody producing cells in chickens (Baba et al. 1998b). In a study, male rats treated with tylosin $(0.1$ and $5.0 \mathrm{mg}$ tylosin $/ \mathrm{kg}$ feed $)$ for three different periods 15,29 and 65 days, showed reduced levels of the luteinizing hormone (LH) and the follicle stimulating hormone (FSH) in the pituitary gland (Meis el et al. 1993a). In contrast, a recent study showed no evidence of decreasing LH secretion in rams when treated with tylosin $10 \mathrm{mg} / \mathrm{kg}$ intramuscularly (Yildiz et al. 2004). Another study also raised the suspicion that tylosin may directly inhibit the intracellular steps of testosterone biosynthesis (Meisel et al. 1993b).

The detailed studies on tylosin are still unclear despite its wide use. Although there are a few reports of the toxicity of tylosin in rats and mammalian cells, they are not sufficient

Address for correspondence:

JeongWoo Kang

Animal and Plant Quarantine Agency

177, Hyeoksin 8-ro, Gimcheon-si, Gyeongsangbuk-do, 39660

Republic of Korea

Phone: +82314671728

E-mail: hijach@korea.kr

http://actavet.vfu.cz/ 
to make a detailed toxicity or safety profile of this drug. Limited information on the toxicological and physiological effects of tylosin leaves a major risk in its application, which might lead to various side effects. For its effective utilization, it is therefore important to evaluate the physiological effects of tylosin on various factors. Thus, the aim of this study was to evaluate the physiological effects of tylosin in vivo in rats.

\section{Animals and treatment}

\section{Materials and Methods}

Pre-pubertal and weaned wistar female and male rats (Charls River Co., Yokohama, Japan) were housed in SPF animal facilities at $23 \pm 1{ }^{\circ} \mathrm{C}$ temperature and $50 \pm 10 \%$ humidity with a $12 \mathrm{~h}$ light/dark cycle. Commercial chow (Purina Laboratory Chow, Seongnam, South Korea) and UV sterilized tap water were provided ad libitum. Tylosin solution was prepared by dissolving tylosin tartrate (Sigma Chemical Co., St. Louis, United States) in distilled water. A group of 6 male [postnatal day (PND) 29] and 6 female (PND 28) rats were administered daily with 0.005, 0.2, 10 and $200 \mathrm{mg} / \mathrm{kg}$ b.w. of tylosin via gavage for 6 weeks. Same numbers of male and female rats as in treated groups were assigned for control groups and were given distilled water instead of tylosin solution. Body weights of rats and their overall feed and water consumption weights were recorded. Previously reported protocols (Beems and van Beek 1985; OECD 1998; Baek et al. 2012) were modified to set up the animal experimental protocol, dosage design, and study time. All animal experimental procedures were approved by the Institutional Animal Care and Use Committee of Animal and Plant Quarantine Agency, South Korea (approval number: 2015-1123).

\section{Blood and tissue collection}

After 6 weeks of tylosin treatment, the feeding was stopped, and the overnight fasted rats were anaesthetized with diethyl ether inhalation. Blood samples were collected from the jugular vein and rats were euthanized by cervical dislocation. Then, the brain, liver, kidneys, lung, thymus, spleen, caecum and adrenal, thyroid and pituitary glands were immediately collected, weighed and fixed in 10\% neutral buffered formalin solution. Tissue samples were examined under light microscopy according to a previously reported procedure (Groelz et al. 2013). Briefly, the tissue sections were cut into $5 \mu \mathrm{m}$ with a microtome and mounted on Microscope Slides. After being air-dried, they were stained with haematoxylin and eosin $(\mathrm{H} \& \mathrm{E})$ and photographed at $\times 40$ magnification by Nikon Diaphot microscope equipped with a high-resolution CCD camera, pseudo dark field illumination, and Nikon Phase $\times 4$ objective. At least two fields per slice and six slices per tissue sample were analysed.

\section{Haematological analysis}

Whole blood $(500 \mu \mathrm{l})$ was added into BD microtainer tube (Becton Dickinson and Company, New Jersey, United States) which contains $\mathrm{K}_{2}$ EDTA, and mixed under roller mixer for $15 \mathrm{~min}$. The sample was then analysed for mean platelet volume (MPV), the percentage of monocytes, neutrophils, lymphocytes, eosinophils and basophils using an automatic haematological analyser (Bayer AG, Leverkusen, Germany).

\section{Biochemical analysis}

The blood samples were left to coagulate under room temperature for $30 \mathrm{~min}$, and serum was separated by centrifugation at $3,500 \times g$ and $4{ }^{\circ} \mathrm{C}$. Alkaline phosphatase (ALP), alanine transaminase (ALT), aspartate transaminase (AST), total cholesterol, low density lipoprotein (LDL), high density lipoprotein (HDL), lactate dehydrogenase (LDH), triacylglycerols, glucose and total bilirubin were analysed with an automated chemistry analyser (Olympus AU400, Tokyo, Japan). The serum immunoglobulin (IgG, IgA, IgM and IgE) levels were analysed for each rat with ELISA quantitation kit (Bethyl Laboratories Inc., Texas, United States) and ELISA reader (Molecular Device Inc., California, United States).

Assay for gene expression in pituitary glands

Total RNA was extracted from pituitary glands using RNeasy Mini kit (Qiagen, Maryland, United States) according to manufacturer's protocol. RNA with the A260/280 value and integrity number higher than 1.9 and 7.5 correspondingly was used for microarray analysis to determine the gene expression. Total RNA was amplified and labelled with one dye, cyanine-3 (DW, tylosin $0.005,0.2,10$ or $200 \mathrm{mg} / \mathrm{kg}$ b.w.) using a Low Input Linear Amplification Kit (Agilent, California, United States) and the labelled cRNA was purified using RNeasy Mini Kit. Each cRNA $(0.75 \mu \mathrm{g})$ was hybridized onto a rat Oligo Microarray slide (44k, Agilent, California, United States) using a Gene Expression Hybridization Kit (Agilent, California, United States) at $70{ }^{\circ} \mathrm{C}$ for $17 \mathrm{~h}$. After hybridization, the slides were washed by $6 \times$ and $0.06 \times$ SSPE with $0.005 \% N$-lauroylsarcosine, and subsequently dried. DNA microarray scanner (Agilent, California, United States) was utilized to scan the dried slides. The resulting data of gene expression were normalized by utilizing the Lowess procedure, and explored by means of GeneSpring GX 7.3 software (Agilent, California, United States).

\section{Statistics}

Data are expressed as mean \pm standard errors of the mean. Comparison between control and treated groups were performed with one-way analysis of variance (ANOVA), followed by Duncan's multiple comparison test. Significance was set at $P<0.05$ and $P<0.01$. 


\section{Results}

\section{Effect of tylosin on overall body and organ weights}

Under the tested conditions, the overall body weights of both female (PND 28-70) and male (PND 29-71) rats administered tylosin tartrate orally $(0.005,0.2,10,200 \mathrm{mg} / \mathrm{kg}$ b.w. of tylosin base) were unchanged for 6 weeks (Table 1). The thymus weights of female rats were significantly $(P<0.05)$ increased when 0.2 and $10 \mathrm{mg} / \mathrm{kg} \mathrm{b.w}$. of tylosin were administered (Table 1). In contrast, the thymus weights of male rats were unchanged. Similarly, the absolute and relative weights of spleen were significantly $(P<0.05)$ increased in male rats when tylosin was administered at doses of 10 and $200 \mathrm{mg} / \mathrm{kg} \mathrm{b.w.,} \mathrm{whereas} \mathrm{the}$ spleen weight was unchanged in female rats (Table 1).

Table 1 . The effect of tylosin on body and organ weights of both male and female rats.

\begin{tabular}{lllllll}
\hline \multicolumn{2}{l}{ Weight in grams } & \multicolumn{1}{c}{ Control } & \multicolumn{1}{c}{ Tylosin 0.005} & \multicolumn{1}{c}{ Tylosin 0.2} & \multicolumn{1}{c}{ Tylosin 10} & \multicolumn{1}{c}{ Tylosin 200 } \\
\hline \multirow{2}{*}{ Body weight } & Male & $358.86 \pm 10.57$ & $350.31 \pm 26.57$ & $353.39 \pm 34.6$ & $382.33 \pm 30.93$ & $359.39 \pm 15.4$ \\
& Female & $231.69 \pm 13.37$ & $230.89 \pm 9.36$ & $232.66 \pm 12.19$ & $245.07 \pm 26.94$ & $237.58 \pm 7.84$ \\
\multirow{2}{*}{ Thymus } & Male & $0.6286 \pm 0.0772$ & $0.5230 \pm 0.0908$ & $0.4860 \pm 0.12$ & $0.6237 \pm 0.1428$ & $0.5226 \pm 0.1258$ \\
& Female & $0.3126 \pm 0.0394$ & $0.3718 \pm 0.0516$ & $0.4314 \pm 0.1048^{*}$ & $0.4607 \pm 0.1089^{*}$ & $0.3946 \pm 0.04$ \\
\multirow{2}{*}{ Spleen } & Male & $0.7956 \pm 0.0856$ & $0.8287 \pm 0.1253$ & $0.8203 \pm 0.1735$ & $1.0424 \pm 0.26^{*}$ & $1.0334 \pm 0.0874 *$ \\
& Female & $0.6196 \pm 0.0832$ & $0.6329 \pm 0.0799$ & $0.6642 \pm 0.0569$ & $0.6444 \pm 0.1123$ & $0.6013 \pm 0.0736$ \\
\hline
\end{tabular}

Rats were administered each dose of tylosin via gavage once per day for 6 weeks. Values are mean \pm standard error of the mean $(\mathrm{n}=6)$. * - significantly different from control at $P<0.05$.

\section{The effect of tylosin on clinical and histopathological findings}

Diarrhoea and caecum enlargement were observed in both male and female rats treated with the highest dose of tylosin $(200 \mathrm{mg} / \mathrm{kg}$ b.w.) whereas no such symptoms were observed in the control and lower doses of tylosin-treated rats. Furthermore, histopathological examinations were performed after 6 weeks of tylosin treatment using the liver, kidney, lung, brain, thymus, spleen, adrenal glands, thyroid glands and pituitary glands. Under the tested conditions, basophilic materials and eosinophilic fluids in tubular epithelial cells of kidneys were found in one or two rats from tylosin-administered groups (Plate IX, Fig. 1).

The effect of tylosin on haematological values

After 6 weeks of tylosin treatment, a significant $(P<0.05$ and 0.01$)$ increase was found in the MPV compared to the control rats (Table 2). All the tested concentrations of tylosin showed effects on MPV of female rats, whereas only 10 and $200 \mathrm{mg} / \mathrm{kg} \mathrm{b}$.w. of tylosin showed a significant increase in MPV of male rats (Table 2). The percentage of monocytes in female rats was reduced at all the tested doses of tylosin, whereas only $200 \mathrm{mg} / \mathrm{kg} \mathrm{b} . \mathrm{w}$. of tylosin were found to be effective $(P<0.01)$ in male rats (Table 2$)$.

Table 2. The effect of tylosin on haematological values.

\begin{tabular}{lllllll}
\hline Indices & & Control & Tylosin 0.005 & Tylosin 0.2 & Tylosin 10 & Tylosin 200 \\
\hline \multirow{2}{*}{ MPV (fL) } & Male & $6.70 \pm 0.09$ & $6.75 \pm 0.12$ & $6.87 \pm 0.19$ & $7.02 \pm 0.08^{*}$ & $7.43 \pm 0.34^{*}$ \\
& Female & $6.85 \pm 0.13$ & $7.30 \pm 0.25^{* *}$ & $7.23 \pm 0.29^{*}$ & $7.38 \pm 0.17^{* *}$ & $7.58 \pm 0.24^{* *}$ \\
WBC & Male & $6.45 \pm 1.04$ & $6.05 \pm 1.09$ & $5.60 \pm 0.89$ & $5.93 \pm 1.28$ & $5.14 \pm 0.76$ \\
$(\times 103$ cells $/ \mu \mathrm{l})$ & Female & $5.15 \pm 1.49$ & $4.45 \pm 1.64$ & $4.43 \pm 0.78$ & $4.26 \pm 1.03$ & $4.15 \pm 1.05$ \\
\multirow{2}{*}{ Monocytes } & Male & $2.86 \pm 0.64$ & $2.18 \pm 0.44$ & $2.15 \pm 0.54$ & $2.08 \pm 1.22$ & $1.28 \pm 0.53^{* *}$ \\
& Female & $3.30 \pm 1.21$ & $1.54 \pm 0.85^{*}$ & $1.67 \pm 0.43^{*}$ & $1.93 \pm 0.73^{*}$ & $1.34 \pm 0.25^{*}$ \\
\hline
\end{tabular}

Rats were administered with each dose of tylosin via gavage once per day for 6 weeks. MPV - mean platelet volume, WBC - white blood cell. Values are mean \pm standard error of the mean $(\mathrm{n}=6) . *{ }^{*} *$ - significantly different from control at $P<0.05$ and $P<0.01$, respectively 
The effect of tylosin on serum proteins

Tylosin with 10 and $200 \mathrm{mg} / \mathrm{kg}$ b.w. in male rats $(P<0.01)$ and $200 \mathrm{mg} / \mathrm{kg}$ b.w. in female rats $(P<0.05)$ caused a significant increase in ALT levels compared to control rats (Plate IX, Fig. 2A,B). Subsequently, a higher dose of tylosin $(200 \mathrm{mg} / \mathrm{kg} \mathrm{b.w.)} \mathrm{also} \mathrm{caused}$ a significant $(P<0.01)$ increase in total serum bilirubin levels in female rats (Plate IX, Fig. 2C). Conversely, tylosin showed a significant $(P<0.05)$ decrease in the LDH concentration in female rats (Plate IX, Fig. 2D).

\section{The effect of tylosin on immunoglobulins}

The effect of tylosin on immunoglobulin (IgG, IgA, IgM and IgE) concentrations was analysed in both male and female rats after they were treated with tylosin for 6 weeks. Under the tested conditions, the IgM concentrations were reduced $(P<0.01$ and 0.05$)$ in both male and female rats after 6 weeks of administration of $0.2,10$, and $200 \mathrm{mg} / \mathrm{kg} \mathrm{b.w}$. of tylosin (Plate X, Fig. 3). The level of IgG was significantly $(P<0.05)$ reduced only in female rats treated with $0.2,10$ and $200 \mathrm{mg} / \mathrm{kg} \mathrm{b.w.} \mathrm{of} \mathrm{tylosin} \mathrm{(Plate} \mathrm{X,} \mathrm{Fig.} \mathrm{3).}$

\section{The effect of tylosin on gene expression profiles in pituitary glands}

The DNA microarray-based assay showed increased expression $(P<0.01$ and 0.05$)$ of genes related with cell proliferation and cell adhesion (Mgst2_predicted, Slcl2a2, Cntn6, CCnb1, Ptk2, etc.) in pituitary glands of female rats. In contrast, the expression of genes related with cell cycle progression or apoptosis (Myc) were significantly $(P<0.01)$ decreased in a dose-dependent manner with tylosin treatment in female rats (Table 3 ). In male rats, the expression of genes related with cell metabolism, protein phosphorylation, G-protein coupled receptor protein signalling pathway and neurotransmission were highly expressed $(P<0.01$ and 0.05$)$ in a dose-dependent manner of tylosin administration (Table 4).

\section{Discussion}

Tylosin did not show any significant effect on the body weight and organ weight except the thymus and spleen, which differed between male and female rats. Body and organ weight change represents the overall health status of the subject. An agent that interferes with the animal's normal growth is considered as toxic (Sellers et al. 2007). The administration of tylosin to mice, rats and dogs at similar doses also did not show any toxic effect. Moreover, tylosin is usually considered safe for long-term use in animals as stated by several studies (Menozzi et al. 2005; Ramlachan et al. 2008; Suchodolski et al. 2009), which is in line with the results of body and organ weights of control and treated rats in our study.

In this study, diarrhoea and caecum enlargement were found with the treatment of the highest dose of tylosin. Recently, a tylosin-associated diarrhoea (TRD) was reported within a few days after tylosin administration (Kilpinen et al. 2011; Papich 2011). Correspondingly, diarrhoea was also observed in our study in rats treated with $200 \mathrm{mg} / \mathrm{kg}$ b.w. of tylosin. Moreover, enlargement of caecum was found in rats with the administration of tylosin $(200 \mathrm{mg} / \mathrm{kg} \mathrm{b.w.)}$ in this study. There were no histopathological abnormalities found in the rat organs (liver, kidney, lung, brain, thymus, spleen, adrenal glands, thyroid glands and pituitary glands) in this study, only except the presence of basophilic materials and eosinophilic fluids in tubular epithelial cells of the kidneys in one or two rats from tylosin-dosed groups. Similarly, no treatment-associated microscopic or gross abnormalities in the liver, lungs, heart, spleen, kidney, skeletal muscle, intestines, stomach, pancreas, salivary gland, gonads, thymus, adrenal, thyroid or mesenteric lymph nodes of rats were observed in a previous study after subcutaneous administration of tylosin tartrate (JECFA 2009). 


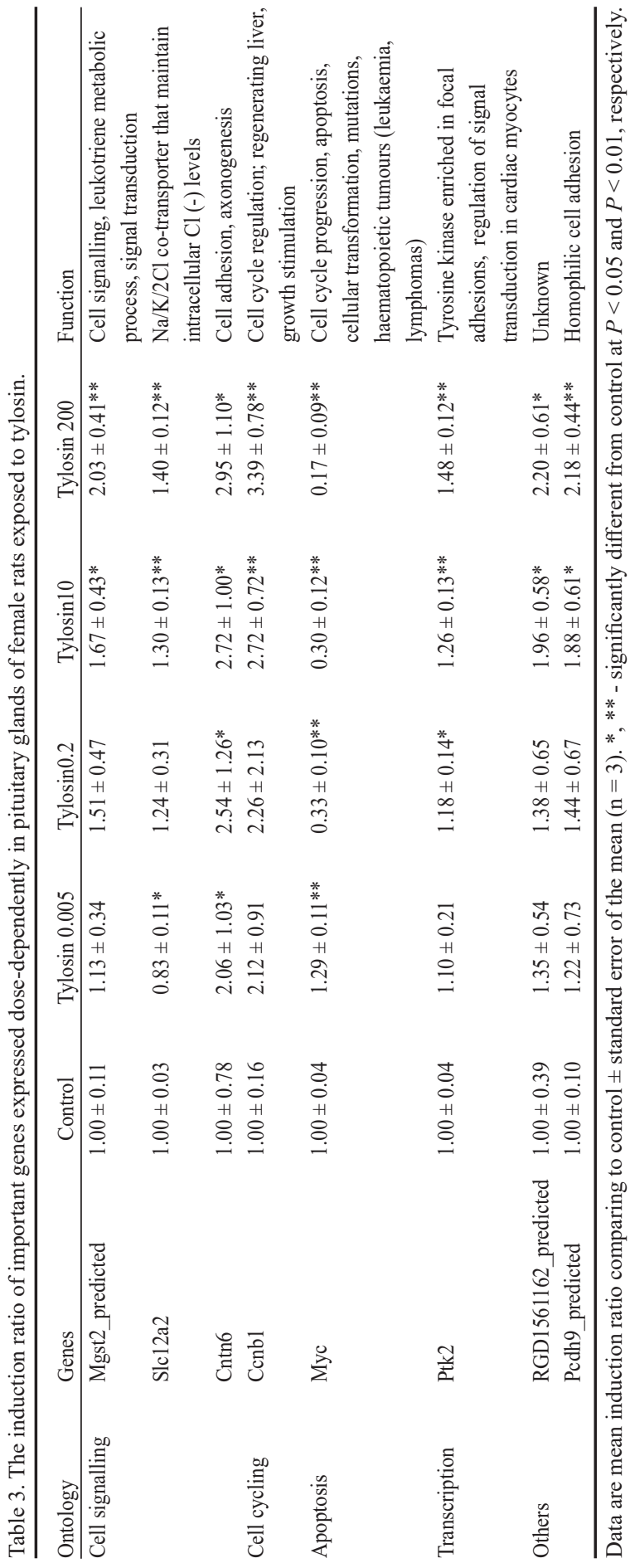

Platelets play an important role in the maintenance of normal homeostasis, and MPV is an indicator of platelet function, including platelet aggregation; release of thromboxane $\mathrm{A}_{2}$, platelet factor 4, and betathromboglobulin; and expression of glycogen $1 \mathrm{~b}$ and glycogen $\mathrm{IIb} / \mathrm{III}$ a receptors. Many studies have shown that increased MPV is one of the risk factors for myocardial infarction, cerebral ischaemia/transient ischaemic attacks, and chronic vascular disease (Ofem et al. 2012). We found that the MPV were increased with tylosin treatment at doses higher than $0.2 \mathrm{mg} / \mathrm{kg}$ b.w. Moreover, the percentages of monocytes were notably reduced in female rats treated with $0.2,10$ and $200 \mathrm{mg} / \mathrm{kg}$ b.w. of tylosin (Table 2). Monocytes are part of the vertebrate innate immune system. When the monocytic cells are at normal counts, they are typically able to repair and remove dead tissue. Low numbers of monocytes may increase the possibility of infections. However, no significant differences were found for haematological values when tylosin tartrate $(0,100,250,500$ or $1000 \mathrm{mg} / \mathrm{kg}$ b.w. per day) was administered subcutaneously to rats in a previous study (JECFA 2009). It is also stated that the complete blood count and serum biochemical profile were within the reference range or there were only minor changes with the administration of $25 \mathrm{mg} / \mathrm{kg}$ of tylosin tablet for 7 days to dogs (Kilpinen et al. 2011).

The activity of aminotransferases in blood is generally low, but it increases rapidly following trauma or necrosis of heart muscles, skeletal muscles, or 


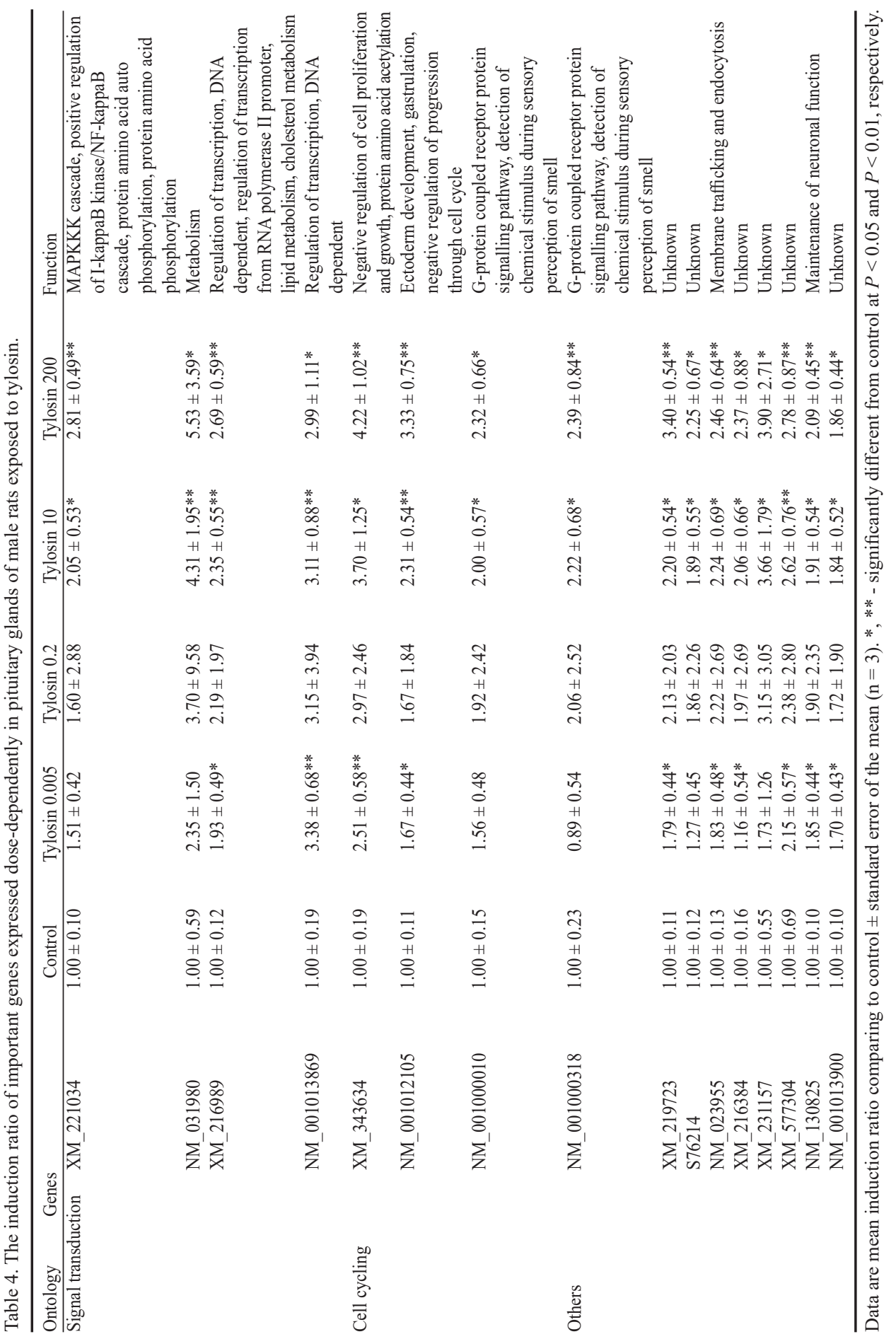


hepatic tissues, as these enzymes diffuse across the damaged cell wall and then enter the circulation. The treatment of tylosin caused a significant increase in the ALT in male and female rats (Fig. 2A and 2B). Elevation of ALT level in blood indicates tissue damage and altered plasma membrane permeability (Satpal et al. 2010). Total serum bilirubin levels in female rats were significantly increased with the treatment of tylosin, indicating that this drug may pertain in liver malfunctioning. Treatment of tylosin $(\geq 0.2 \mathrm{mg} / \mathrm{kg} \mathrm{b.w.)}$ significantly decreased LDH concentration in female rats in this study. Deficiency of LDH causes fatigue, muscle pain, and cramps, which lead to rhabdomyolysis, myoglobinuria, kidney failure and skin rashes (JECFA 2009). The IgM levels were decreased in both male and female rats after 6 weeks administration of $0.2,10$ and $200 \mathrm{mg} / \mathrm{kg} \mathrm{b.w}$. of tylosin (Fig. 3). Low levels of IgM are associated with increased risk of infections. However, significantly reduced IgG levels were found only in female rats which were treated with tylosin for 6 weeks.

The treatment of tylosin increased the expression of cell proliferation and cell adhesion associated genes and reduced the expression of cell cycle progression or apoptosis related genes. Increased expressions of cell proliferation and cell adhesion associated genes and reduced expressions of cell cycle progression or apoptosis related genes are also reported in previous studies (Dorotheou et al. 2017; Hofmann et al. 2015). The result of gene expression indicates that the tested concentration of tylosin has no adverse effects on general cell development. From the above discussion it can be concluded that the therapeutic dose of tylosin is not completely free of complications. We believe that the data of the current study may be useful to decide on the safe use of tylosin in animals. However, further investigations involving different animal species are recommended to establish a detailed safety profile of this drug.

\section{Acknowledgement}

This work was supported by the grant No. B-1543073-17-0101 from the Animal and Plant Quarantine Agency, Ministry of Agriculture, Food, and Rural Affairs, Republic of Korea.

\section{References}

Baba T, Yamashita N, Kodama H, Mukamoto M, Asada M, Nakamoto K, Nose Y, McGruder ED 1998a: Effect of tylosin tartrate (tylan soluble (R)) on cellular immune responses in chickens. Poult Sci 77: 1306-1311

Baba T, Yamashita N, Kodama H, Mukamoto M, Asada M, Nakamoto K, Nose Y, McGruder ED 1998b: Effect of tylosin tartrate on humoral immune responses in chickens. J Vet Med B 45: 279-286

Baek YO, Choi SK, Shin SH, Koo KH, Choi HY, Cha SB, Li YC, Yoo HJ, Lee JY, Kil KH, Kim HS, Kang MS, Kang BH, Kim KH, Bae JS 2012: A 6-week oral toxicity study of oral cholera vaccine in sprague-dawley rats. Toxicol Res 28: 225-233

Baggesen DL, Wingstrand A, Carstensen B, Nielsen B, Aarestrup FM 1999: Effects of the antimicrobial growth promoter tylosin on subclinical infection of pigs with Salmonella enterica serotype Typhimuriumm. Am J Vet Res 60: 1201-1206

Beems RB, van Beek L 1985: Short-term (6-week) oral toxicity study of selenium in Syrian hamsters. Food Chem Toxicol 23: $945-947$

Bhaumik A, Verma BB, Thakur DK, Pandey SN, Banerjee NC 1990: Effect of oral-administration of tylosin tartrate in the treatment of experimental and natural cases of caprine mycoplasmosis. Indian Vet J 67: 948-951.

Dorotheou D, Farsadaki V, Bochaton-Piallat ML, Giannopoulou C, Halazonetis TD, Kiliaridis S 2017: Increased cell proliferation and gene expression of genes related to bone remodeling, cell adhesion and collagen metabolism in the periodontal ligament of unopposed molars in growing rats. Front Physiol 8: 75

Groelz D, Sobin L, Branton P, Compton C, Wyrich R, Rainen L 2013: Non-formalin fixative versus formalin-fixed tissue: A comparison of histology and RNA quality. Exp Mol Pathol 94: 188-194

Hofmann JW, Zhao X, Cecco MD, Peterson AL, Pagliaroli L, Manivannan J, Hubbard GB, Ikeno Y, Zhang Y, Feng B, Li X, Serre T, Qi W, Remmen HV, Miller RA, Bath KG, de Cabo R, Xu H, Neretti N, Sedivy JM 2015: Reduced expression of MYC increases longevity and enhances healthspan. Cell 160: 477-488

JECFA - Joint FAO/WHO Expert Committee on Food Additives 2009: Toxicological evaluation of certain veterinary drug residues in food. World Health Organization, Geneva, WHO Technical Report Series: 954

Kilpinen S, Spillmann T, Syrjä P, Skrzypczak T, Louhelainen M, Westermarck E 2011: Effect of tylosin on dogs with suspected tylosin-responsive diarrhea: a placebo-controlled, randomized, double-blinded, prospective clinical trial. Acta Vet Scand 53: 26 
McOrist S, Morgan J, Veenhuizen MF, Lawrence K, Kroger HW 1997: Oral administration of tylosin phosphate for treatment and prevention of proliferative enteropathy in pigs. Am J Vet Res 58: 136-139

Meisel ML, Winterhoff H, Jekat FW 1993a: Effects of tylosin on the pituitary-gonadal axis in male rats. Basic Clin Pharmacol Toxicol 72: 336-340

Meisel ML, Winterhoff H, Jekat FW 1993b: Tylosin inhibits the steroidogenesis in mouse leydig cells "in vitro". Life Sci 53: 77-84

Menozzi A, Pozzoli C, Poli E, Lazzaretti M, Cantoni A, Grandi D, Giovannini E, Coruzzi G 2005: Effect of the macrolide antibacterial drug, tylosin, on TNBS-induced colitis in the rat. Pharmacol 74: 135-142

OECD - Organisation for Economic Co-operation and Development 1998: Guideline for the testing of chemicals. Repeated dose 90-days oral toxicity study in rodents, $408 \mathrm{p}$.

Ofem OE, Ani EJ, Eno AE 2012: Effect of aqueous leaves extract of Ocimum gratissimum on hematological parameters in rats. Int J Appl Basic Med Res 2: 38-42

Papich MG 2011: Saunders handbook of veterinary drugs small and large animal. $3^{\text {rd }}$ edn. Elsevier Saunders, Missouri, $896 \mathrm{p}$.

Ramlachan N, Anderson RC, Andrews K, Harvey RB, Nisbet DJ 2008: A comparative study on the effects of tylosin on select bacteria during continuous flow culture of mixed populations of gut microflora derived from a feral and a domestic pig. Foodborne Pathog Dis 5: 21-31

Satpal, Jain SK, Punia JS 2010: Studies on biochemical changes in subacute thiodicarb toxicity in rats. Toxicol Int 17: 30-32

Sellers RS, Morton D, Michael B, Roome N, Johnson JK, Yano BL, Perry R, Schafer K 2007: Society of toxicologic pathology position paper: organ weight recommendations for toxicology studies. Toxicol Pathol 35: 751-755

Suchodolski JS, Dowd SE, Westermarck E, Steiner JM, Wolcott RD, Spillmann T, Harmoinen JA 2009: The effect of the macrolide antibiotic tylosin on microbial diversity in the canine small intestine as demonstrated by massive parallel 16S rRNA gene sequencing. BMC Microbiol 9: 210

Vissiennon T, Kroger H, Kohler T, Kliche R 2000: Effect of avilamycin, tylosin and ionophore anticoccidials on Clostridium perfringens enterotoxaemia in chickens. Berl Muench Tieraerztl Wochenschr 113: 9-13

Yildiz S, Ozturkler Y, Uzun M, Kaya M, Ucar O 2004: Tylosin does not affect GnRH-induced LH secretion in rams. Reprod Toxicol 18: 131-134 
Plate IX

Kang J.W. et al.: Physiological... pp. 283-290

A

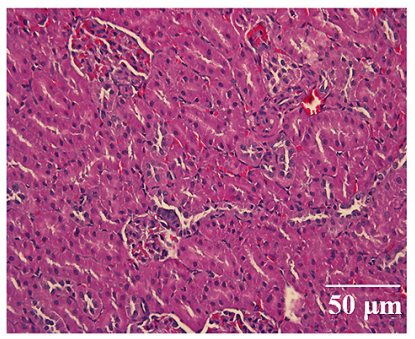

B

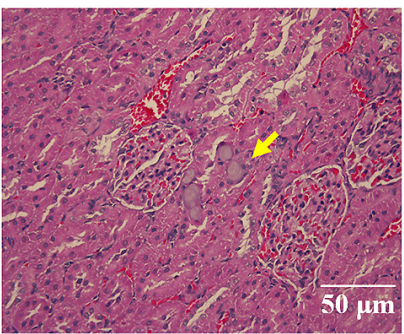

C

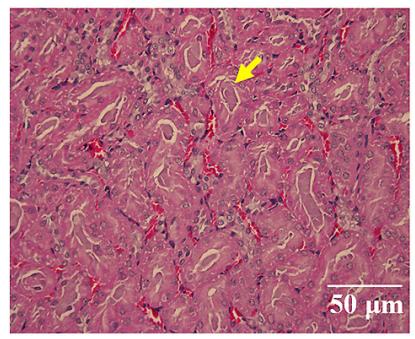

Fig. 1. Histopathological findings of the rats' kidneys ( $\times 40$ magnification $)$. A - Tubular epithelium of a control rat. B, C - infiltration of basophilic materials and eosinophilic fluids, respectively, in the tubular epithelium of kidneys of female rats treated with tylosin $200 \mathrm{mg} / \mathrm{kg}$ b.w./day for 6 weeks.

A

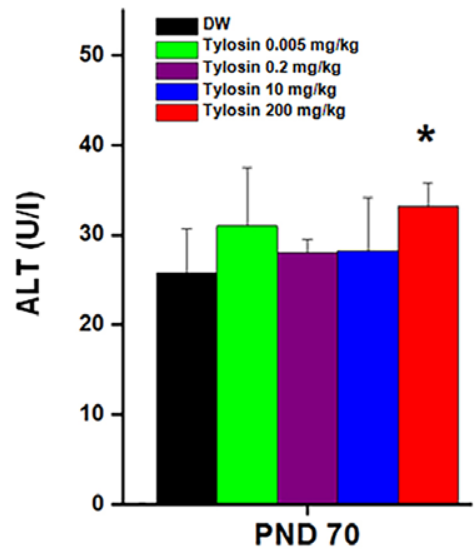

\section{C}

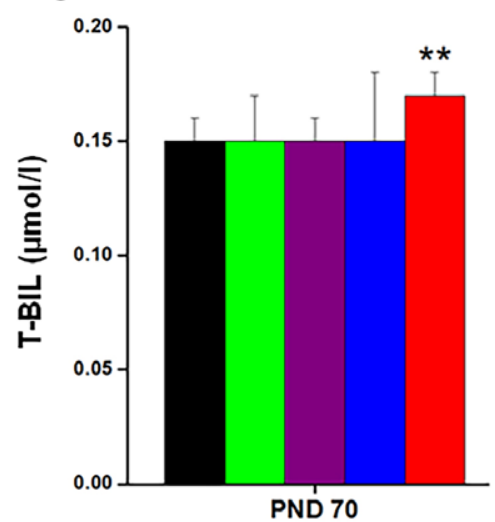

B

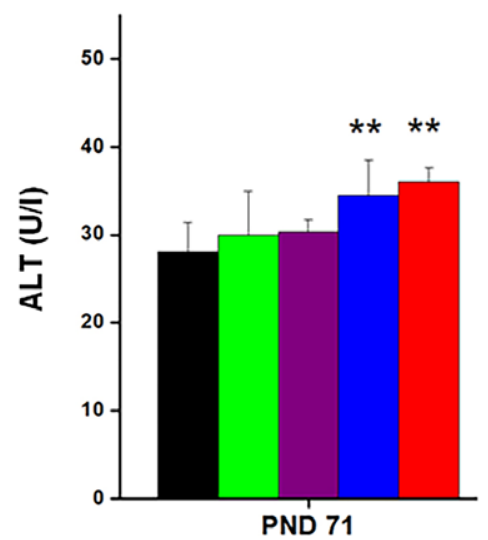

D

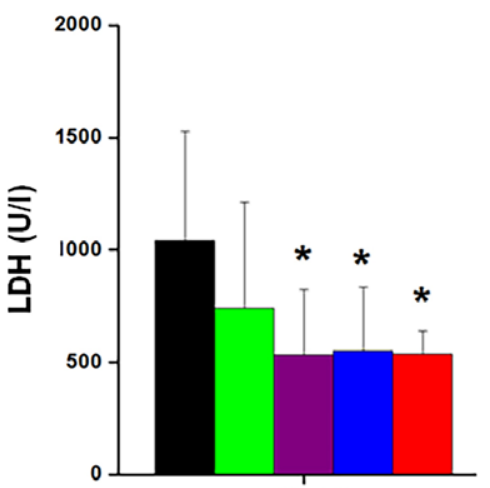

PND 70

Fig. 2. Effects of tylosin on various serum biochemical indices. A, B - changes of serum alanine transaminase (ALT) concentrations in Wistar female [postnatal day (PND) 70] and male (PND 71) rats, respectively. C, D - changes of total serum bilirubin (T-BIL) and lactate dehydrogenase (LDH), respectively, in Wistar female rats (PND 70). DW - distilled water; *, **: Significantly different from control at $P<0.05$ and $P<0.01$, respectively. Rats were treated with different doses of tylosin and samples were collected and measured after 6 weeks of administration. Values are mean \pm standard error of the mean $(n=6)$. 


\section{Plate X}

A

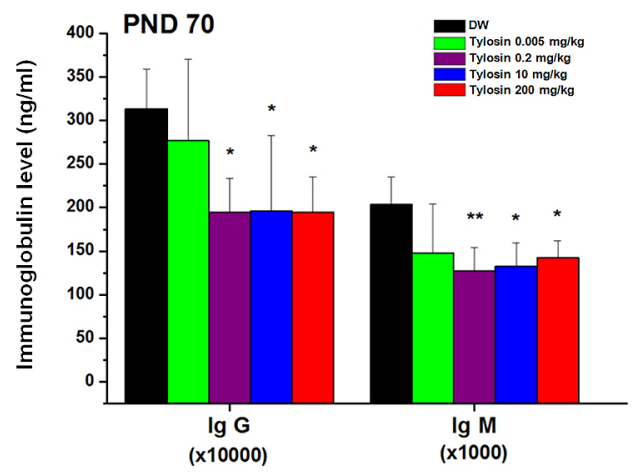

B

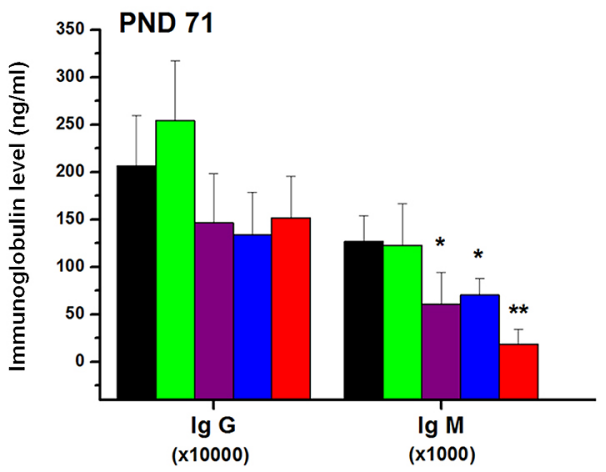

Fig. 3. Effect of tylosin on immunoglobulins. Changes of immunoglobulin (IgG and IgM) concentrations in Wistar female [postnatal day (PND) 70] and male rats (PND 71). DW: distilled water; *, **: Significantly different from control at $P<0.05$ and $P<0.01$, respectively. Values are the mean $\pm \mathrm{SE}(\mathrm{n}=6)$. 